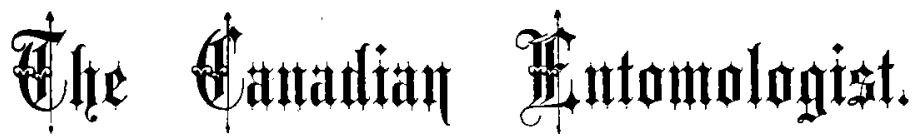

$\begin{array}{lll}\text { Vol. XXXIII. IJONDON, JULY, I901. } & \text { No. } 7\end{array}$

NOTES ON THE LIFE-HISTORY OF ALSOPHILA POMETARIA, Peck.

(Fall Cankerworm.)

PY W. E. HINDS, B. S., ENTOMOLOGICAL LABORATORY OF THE MASSACHUSETTS AGRICULTURAL COLLEGE, AMHERST, MASS.

The eggs of this insect were found on a small branch of golden willow in Beverly, Mass., March I4, I900, in a nursery, close to fruit stock of various kinds. The mass, consisting of 220 eggs, was kept at the temperature of the laboratory, which was considerably higher than that outside. Notwithstanding this fact, none of the eggs hatched till April 23, within forty-eight hours of which time, however, all the larvæ had emerged.

Egg (Plate 4, Figs. I and 3).-Eggs placed close together in regular rows, forming a compact mass, in this case about twice as long as broad and in one layer. Egg about $.6 \mathrm{~mm}$. long and $.45 \mathrm{~mm}$. broad at top, which is nearly flat. Just inside the rounded edge of the top a brown ring encloses an area bright steely gray in colour, and containing a smail brown depression in its centre; lateral surface of egg and rounded edge steely gray. Base of egg more rounded than top, and its diameter somewhat less, as the straight sides converge slightly toward the base, giving to the whole a resemblance to an inverted truncate cone with rounded basal edge. Eggs laid in an exposed position upon the tree, and quite firmly cemented together; placed in a somewhat slanting position lengthwise of the twig, so that the edge of one is a little higher or lower than the adjacent edge of the next in the row.

Larva.-Emergence-When ready to emerge from the egg, the tiny larva makes its first meal upon the relatively thinner portion of the shell constituting the steely-gray area enclosed by the brown ring. Through the opening thus made in the top of the egg, the young larva gradually and laboriously works its way out. At this time the head is the largest segment, the body tapering very slightly from it to the tip of 
the abdomen. The head and thorax are slowly worked up out of the shell until the legs can be of some assistance in pulling, after which the rest of the process is relatively easy and rapid. The length of time required to emerge after the central area of the shell has been completely removed varies from thirty minutes to one hour, after which the larva immediately starts off in search of food.

The larvæ were placed upon tender apple leaves, and commenced feeding at once. A slight jar caused many of them to spin down from the twig to the table, where they showed a decided tendency to travel toward the light.

Newly-hatched Larva (Plate 4, Fig. 2).-Length at rest, $1.5 \mathrm{~mm}$; width of head, $.33 \mathrm{~mm}$; average diameter of body, .25 mm. Head large, roundied, nearly as wide as high, of a uniform yellow colour, darker than rest of body ; clypeus triangular, marked by brown sutures; mandibles tipped with black. Head sparsely clothed with comparatively long, white hairs having blunt extremities; antennæ comparatively long; head free, erect. Body nearly cylindrical, tapering very slightly posteriorly from head; annulations not very distinct; segments somewhat shorter than their diameter; prolegs present on abdominal segments 7 and 10 , with vestiges of a pair upon sixth abdominal segment. Cervical shield prominent, of same colour as head, and with a light yellow border, which is set with ten spines (Fig. 7 A). Arrangement of the tubercles, as

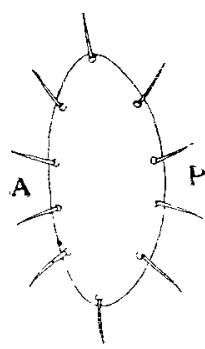

A

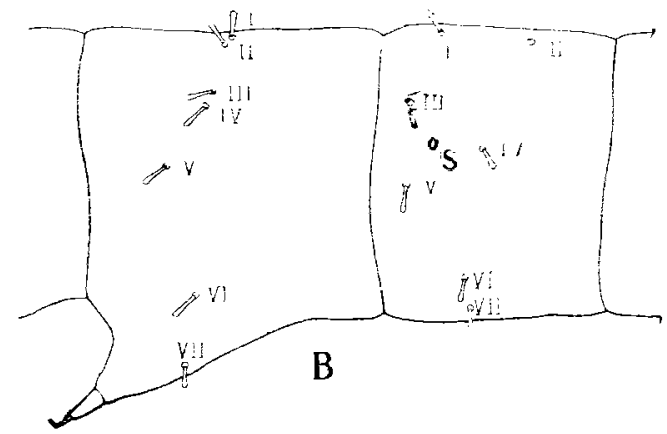

FIG 7--Arrangement of tubercles and spines upon the larva of Anisopteryx pometaria, Harr., first instar. A : cervical shield on dorsum of prothorax; $A$, anterior side; $P$, posterior side. B : metathoracic and first abdominal segments; I.-VII., tubercles and spines, according to Dyar's classification; s, spiracle.

shown in Fig. 7 B, differs upon the thorax from that prevailing upon the abdomen; tubercles on prothorax and 9 th and roth abdominal segments 
not conforming to either arrangement. Upon meso- and metathorax, tubercle II. stands laterally close to tubercle 1 . upon the subdorsal line, and tubercles III. and IV. stand in similar relation upon the sublateral line; other tubercles upon these segments well separated and situated in nearly the same transverse line; upon the abdomen, with the exception of $9^{\text {th }}$ and roth segments, tubercles I. and II. stand longitudinally upon the subctorsal line, II. being slightly further from the dorsal line than I.; tubercles III., IV. and V. are separated, and form the apices of a triangle around the spiracle, which, upon the first abdominal segment, stands very near the centre of this triangle, but upon the other segments it stands in line with III. and IV., and midway between them; thus IV. is sub-postspiracular, while IIJ. and V. are on the anterior third of the segment; tubercles VI. and VII. present.

Stripes much less distinct than in later stages; dorsal, lateral and stigmatal stripes brownish gray, apparently due to numerous evenlyscattered pigment spots in the epidermis; intermediate stripes (subdorsal, sublateral and substigmatal) pale yellow. Stripes irregular in outline, of different widths, dorsal stripe widest. Upon the abdomen tubercles I. and II. stand between the dorsal and subdorsal, III. in the sublateral, and IV. and V. in the stibstigmatal stripe; tubercles light brown in colour, each bearing a short, white, blunt spine. Stripes become indistinct during this instar, which lasts four days.

Second Instar.-During the two or three days following the first moult the average length of larvæ at rest increases to about $7 \mathrm{~mm}$., while at the end of this instar the average is about $8 \mathrm{~mm}$.

Segmentation now fairly distinct. Head rounded, colour mottled light and dark greenish; mandibles serrate, tipped with reddish brown; clypeal sutures distinctly marked; antennæ and palpi tipped with brown.

General colour of body light green, with six longitudinal white stripes alternating with dark green ones; dorsal stripe dark, broadest and darkest upon the cervical shield. Tubercles I. and II. stand in edge of dark dorsal stripe, III. in upper edge of dark stigmatal stripe; leg shields with a V-shaped dark marking.

General colour of under surface of abdomen light green. Pair of vestigial prolegs upon sixth abdominal segment more prominent than in first instar ; each segment bearing no prolegs furnished with tubercles VI. and VII., as in previous instar.

Soon after hatching, the larvæ were divided into two lots, one of 
which was kept under a bell jar, while the other was enclosed in a breeding cage. At the end of the second instar a marked difference was observed in the rapidity of development of the two lots. All the larva confined beneath the bell jar passed through the second ecdysis before one of those in the breeding cage had reached that point. The only observable difference in conditions was a greater abundance of moisture beneath the bell jar, which would naturally improve the food by keeping it fresh and tender. The second instar thus ranged from 5 to 7 days.

Third Instar. - The second ecdysis produced a marked change in colour in larvæ: the light green became dark green, and the light yellow stripes were much more conspicuous.

Two Days After Moult.-Average length at rest about $12 \mathrm{~mm}$; form as before. General colour varied from dark brownish-green to as light green as in previous instar ; in light-coloured specimens, however, the broad dorsal stripe is much darker than the other stripes, and also darker than it was in the second instar.

Clypeus and labrum usually lighter coloured than rest of head; head somewhat mottled with green; antennæ at their bases as light coloured as labrum; mandibles yellow, tipped with black.

Spines and stripes present as in previous instars; substigmatal white stripe has become broader, and tubercles IV. and V. stand therein; spiracles conspicuous, dark brown.

The third moult took place in about six days after the second, and produced a great change in the appearance of the larræ. It required less than forty-five minutes to get rid of the old skin after it began to rupture around the throat.

Fourti Instar.-Two Days After the Moult.—Length at rest about I $8 \mathrm{~mm}$; form cylindrical, segmentation distinct. Head equal in size to any following segment, rounded, mottled brown and light green in colour, darkest on sides of lobes; clypeus triangular, extending nearly to head, its vertex connected by a light-coloured depression, with vertex of a white triangular area lying on top of head between the lobes; antennæ and labrum light coloured. The wide variation between light and dark specimens noticed in last instar has disappeared, so that the coloration has become quite uniform in different individuals ; body marked with dark brown and white stripes; dorsal stripe broad and dull blackish in colour; subdorsal white stripe clearly defined, quite narrow; lateral stripe, which was dark in previous instars, has become changed almost 
entirely to light geenish-white, with slight traces of the old dark stripe remaining along its edges; sublateral white stripe narrow and distinct; stigmatal stripe nearly black and irregular in width, being narrowed between segments and broadened around stigmata; substigmatal stripe white, below this there is still another dark stripe which is interrupted between the segments; anal plate light coloured and set with numerous spines. Tubercles and spines upon body as in previous stages, but less conspicuous on account of darker colour of body; each tubercle terminated by a shining black ring around base of spine borne thereon ; each stigma marked by a shining black, oval border, enclosing white area in centre.

Venter light green; thoracic legs somewhat yellowish, claws brownish; prolegs concolorous with venter or with slightly yellowish tinge; prolegs upon fifth abdominal segment vestigial in all stages, crotchets upon them arranged around end of leg in the form of a horseshoe opening outwardly (Fig. 4); of the eight or nine little crotchets on each vestigial proleg, the three posterior ones are largest; each proleg of the two functional pairs bears crotchets arranged in two groups of from 7 to 9 each at the extremities of a crescentic or semicircular pad borne upon inner side of tip of proleg, with its convex edge inward (Fig. 5). The crotchets vary in length alternately, thus forming two rows of hooks; along the convex edge of pad between the two groups are vestiges of from 8 to 14 more crotchets. (Plate 4, Fig. 6.)

Moulting.-As the larva approached a moult, it ceased to feed, became quiet for a time, which was longest before the third moult, lasting then for nearly two days, and when fully ready to shed its skin, firmly attached its prolegs, let go with its thoracic legs, and stood out at an angle to its slipport. Successive contractions now took place in various parts of the body, the thoracic legs were withdrawn and the skin stretched backward, after which the skin began to rupture on the ventral side of the throat, and through this transverse opening the under side of the prothorax appeared, the rupture continuing around the throat thus severed the old head-covering entirely from the rest of the integument. The thorax was soon freed, and by successive expansions and contractions of the body running backward with a wavelike motion the skin was drawn back over most of the abdominal segments. When about half the length of the body had been thus freed, the old head integument, which had in the meantime remained attached to the head over the mouth-parts, 
was seized between the fore legs, pulled off and cast aside. As soon as the first pair of functional prolegs were free, they were moved forward and attached to the support, and by a gentle pull the rest of the body was quickly withdraw1. The tender larva then moved on a short distance and stopped to rest before proceeding to feed.

During the fourth instar the larvæ fed very heartily, becoming large and fat, but toward the end of the instar they became sluggish and fed but little. In from nine to twelve days they entered the ground to pipate. After two days, two of the larvæ were dug up and examined. They had formed little ellipsoidal cases of particles of earth held together by a loose silken lining, and apparently also by some mucilaginous substance. The cocoons were quite tough, slightly less than half an inch in length, and within them the larvæ were doubled up, as they were about half as long again as the cocoons, but after five days they had not pupated.

On May 28 it became necessary to discontinue the observations, so the large flowerpot containing the pupæ-pupating larvæ-was set in the ground in a sheltered place where it would receive a normal amount of moisture, so that its top stood even with the surface of the ground. A fine wire screen was placed over the pot to prevent the escape of the adults when they should emerge.

During September and October frequent observations were made to determine at just what time the adults emerged, but as none appeared, an examination was finally made. Twenty-five cocoons were found at depths ranging from $\mathrm{I} / 2$ to 4 inches, but the majority were not more than two inches deep. Each cocoon showed a small round hole through which some enemy had entered and destroyed the pupa. It is probable that the damage was done by small red ants (a species of Monomorium), as these were known to have destroyed other pupæ in the vicinity during the summer. The date of emergence of the adults could not, therefore, be determined, but this is a comparatively unimportant point, as it is well known that the majority of them emerge during the last part of October and the first of November.

\section{Explanation of Plate 4.}

Fig. I.-Small group of eggs of Alsophila pometaria, Peck., 5/r.

Fig. 2.-Newly-hatched larva, 26/1.

Fig. 3.-Top view of eggs, $42 / \mathrm{r}$. 
Fig. 4.-Tip of vestigial proleg showing crotchets, much enlarged.

Fig. 5.-Crotchets of functional proleg, highly magnified.

Fig. 6.-Crotchets of functional proleg arranged in two groups, with vestigial bases of crotchets between them.

\section{FURTHER ABOUT 'THE TYPES OF ACRONYCTA.}

BY HARRISON G. DYAR, WASHINGTON, D. C.

Prof. Smith's remarks in the May Canadian EnTomologist contain two separate counts. He implies that I might be led by personal views to an improper treatment of the collection in my charge. This implication I indignantly repudiate, and leave Prof. Smith to explain his breach of etiquette as best he may. While Prof. Smith's lack of humour has led him to misunderstand my views, he has no right to imply that with any personal views whatever I would not properly conserve the National Collection. This collection, rapidly becoming the finest in the country, will continue to be conserved with the greatest care. As to the synonymy of the Acronyctas, Prof. Smith makes two assumptions. First, that the specimens now in the British Museum labeled as Guenée's types are still as labeled and described by him; second, that if so, they are properly types. As to the first assumption, I am not in a position at present to dispute it, though I think that some admixture or confusion might have easily arisen in transference, and considering the length of time that has passed. As to the second assumption, I regard it as debatable in the cases where Guenée described larvæ. In such cases, under the most favourable conditions, Guenée had before him Abbot's figure of a moth and larva and some specimens which Guenée himself thought to be the same species. Suppose in one of the cases under discussion that Guenée had before him Abbot's figure of the moth and larva of subochrea and also adult specimens of afficta; that he regarded all as of one species and drew up a description under the name hamamelis. Now, if this description agrees with subochrea, and does not agree with afficta, what is the type of Guenée's hamamelis? Clearly it is Abbot's drawing and not the specimens labeled by Guenée. Are we to be blindly led by a specimen labeled "type," which may be white, while the description is black? Is not what the author described and intended to count for something? I am a believer in types, and where they are certainly the specimens from which the author described, I would regard them as of high value. Walker's types are invaluable, and I never supposed that anyone would 